\title{
Tomografia computadorizada das células etmoidais intra e extramurais: ensaio iconográfico*
}

\author{
Computed tomography of intra- and extramural ethmoid cells: iconographic essay
}

Fabrício Guimarães Gonçalves ${ }^{1}$, Cássio Lemos Jovem ${ }^{2}$, Leonardo de Oliveira Moura ${ }^{3}$

\begin{abstract}
Resumo O desenvolvimento dos seios paranasais é um processo intricado que se inicia na vida intrauterina e termina na idade adulta. Dos seios da face, as células etmoidais são provavelmente as estruturas mais complexas e as que estão associadas com o maior número de variantes da normalidade. Variações no padrão de pneumatização das células etmoidais podem ser divididas em intra ou extramurais. Intramurais são aquelas que ao se desenvolverem mantêm contato com o labirinto etmoidal, e extramurais as que se desenvolvem isoladamente. A tomografia computadorizada é a ferramenta mais útil na avaliação de processos inflamatórios dos seios paranasais. De igual modo, ela é importante para o planejamento pré-operatório e controle pós-operatório, pois possibilita grande detalhe anatômico das estruturas normais e detecção precisa de suas variantes. Neste ensaio iconográfico os autores descrevem as principais variantes da normalidade do labirinto etmoidal e suas relações com estruturas adjacentes. Cirurgias endoscópicas para o tratamento de afecções dos seios paranasais têm-se tornado cada vez menos invasivas, o que certamente aumentará a demanda por relatórios de imagem cada vez mais ricos em detalhes desta região.
\end{abstract}

Unitermos: Tomografia computadorizada; Seio etmoidal.

\begin{abstract}
The development of the paranasal sinuses is an intricate process that begins in the intrauterine life and terminates in early adulthood. Among the paranasal sinuses, the ethmoid cells or labyrinth are probably the most complex structures, being associated with the highest number of normal variants. Variations in the pattern of pneumatization of the ethmoid cells can be divided into intra- and extramural cells. Intramural cells are those which develop within the ethmoid labyrinth. Extramural cells are those that develop isolatedly. Computed tomography is the most useful tool in the evaluation of inflammatory processes of the paranasal sinuses. Computed tomography also plays a relevant role in the preoperative planning as well as in the postoperative follow-up, since it demonstrates exact anatomical details of normal structures with accuracy in the detection of variants. In the present pictorial essay, the authors describe the most common anatomical variants of the ethmoid labyrinth and their relationship with adjacent structures. Endoscopic sinonasal surgery has become increasingly less invasive, requiring more detailed anatomical imaging of this region.
\end{abstract}

Keywords: Computed tomography; Ethmoid sinus.

Gonçalves FG, Jovem CL, Moura LO. Tomografia computadorizada das células etmoidais intra e extramurais: ensaio iconográfico. Radiol Bras. 2011 Set/Out;44(5):321-326.

\section{INTRODUÇÃO}

A tomografia computadorizada (TC) é considerada o método de escolha na avalia-

* Trabalho realizado no McGill University Health Center (MUHC), Montreal General Hospital, Montreal, Quebec, Canadá.

1. Médico Radiologista, Membro Titular do Colégio Brasileiro de Radiologia e Diagnóstico por Imagem (CBR), Clinical Fellow em Neurorradiologia, McGill University Health Center (MUHC), Montreal General Hospital, Montreal, Quebec, Canadá.

2. Médico Radiologista, Fellow em Neurorradiologia, Med Imagem - Hospital Beneficência Portuguesa de São Paulo, São Paulo, SP, Brasil.

3. Médico Radiologista, Membro Titular do Colégio Brasileiro de Radiologia e Diagnóstico por Imagem (CBR), Cetrim - Centro de Treinamento em Imagenologia, Ecoclínica Multi Diagnose, João Pessoa, PB, Brasil.

Endereço para correspondência: Dr. Fabrício Guimarães Gonçalves. Department of Diagnostic Radiology, Montreal Genera Hospital. 1650 Cedar Avenue, Room D5 137, Montreal, Quebec, Canada H3G 1A4. E-mail: goncalves.neurorradio@gmail.com

Recebido para publicação em 11/3/2011. Aceito, após revisão, em 24/8/2011. ção dos processos inflamatórios não complicados dos seios paranasais ${ }^{(\mathbf{1}, \mathbf{2})}$. Além disso, A TC é extremamente útil no planejamento pré-operatório e no controle pós-cirúrgico das cirurgias endoscópicas endonasais por fornecer importantes detalhes da anatomia normal e das variantes anatômicas $^{(\mathbf{3 , 4})}$. Mais recentemente, reconstruções multiplanares e tridimensionais têm sido usadas como parte da rotina no estudo dos seios paranasais, por exibirem imagens de melhor qualidade diagnóstica e informações superiores à TC convencional, principalmente na identificação de algumas variantes anatômicas ${ }^{(4-6)}$. Variantes anatômicas originárias do processo de desenvolvimento das células etmoidais são as mais comuns, frequentemente associadas a pro- cessos inflamatórios e responsáveis pela maioria das revisões cirúrgicas dos seios paranasais $^{(\mathbf{7 - 1 0})}$.

Já presentes ao nascimento, as células etmoidais se desenvolvem de maneira heterogênea e variável até o início da vida $\operatorname{adulta}^{(\mathbf{1 1})}$. Nas diferentes etapas do processo de desenvolvimento do labirinto etmoidal surgem dois principais grupos de variantes da normalidade: as células etmoidais extramurais e as intramurais. Células etmoidais extramurais são estruturas que se pneumatizam e se desenvolvem projetando-se externamente ao corpo do labirinto etmoidal. Fazem parte deste grupo as células do agger nasi, as células frontais, as células etmoidais supraorbitais e as células de Haller e de Onodi. Por sua vez, células 
etmoidais intramurais são estruturas que se pneumatizam e continuam intimamente relacionadas ao labirinto etmoidal, caracterizadas pelas células frontais bullares, células suprabullares e bulla etmoidal $^{(\mathbf{1 2})}$. O reconhecimento das diferentes variantes anatômicas dos seios paranasais nos exames de imagem é de fundamental importância para o rinologista. Em razão da sua proximidade com as principais vias de drenagem dos seios paranasais, algumas células podem reduzir o clearance mucociliar, predispondo a processos inflamatórios e serem responsáveis por revisão de cirurgias endoscópicas endonasais.

Neste ensaio iconográfico os autores descrevem em detalhes as células etmoidais extramurais e intramurais, com imagens ilustrativas. Enfatizam, ainda, alguns aspectos importantes da unidade ostiomeatal, recesso frontal e recesso esfenoetmoidal, estruturas de grande importância na drenagem mucociliar dos seios paranasais. As imagens deste ensaio foram selecionadas de exames de TC dos seios paranasais de pacientes provenientes do ambulatório de otorrinolaringologia do Hospital Universitário de Brasília, pelos autores F.G.G. e C.L.J., com oito e três anos de experiência radiológica. Todos os exames dos seios paranasais foram realizados com aquisição volumétrica em aparelho de TC com multidetectores de quatro canais. As imagens foram revisadas e reconstruídas em múltiplos planos em estações de trabalho GE Advantage 4.2.

\section{Unidade ostiomeatal e recessos frontal e esfenoetmoidal}

Unidade ostiomeatal é a via comum de drenagem dos seios paranasais anteriores, atuando como uma unidade funcional que controla e modula a drenagem mucociliar dos seios frontais, células etmoidais anteriores e seio maxilar. É composta pelas estruturas: processo uncinado, bulla etmoidal, concha média, além dos espaços entre essas estruturas (infundíbulo etmoidal, hiato semilunar e meato médio) (Figura 1) ${ }^{(\mathbf{1 3}, \mathbf{1 4})}$.

O recesso frontal é a via de drenagem dos seios frontais. Cada recesso frontal é rodeado pelas seguintes estruturas: células do agger nasi, bulla etmoidal, corneto médio, lamela basal e células etmoidais anteriores $^{(\mathbf{1})}$ (Figura 2). O recesso esfenoetmoidal é via de drenagem do seio esfenoidal,

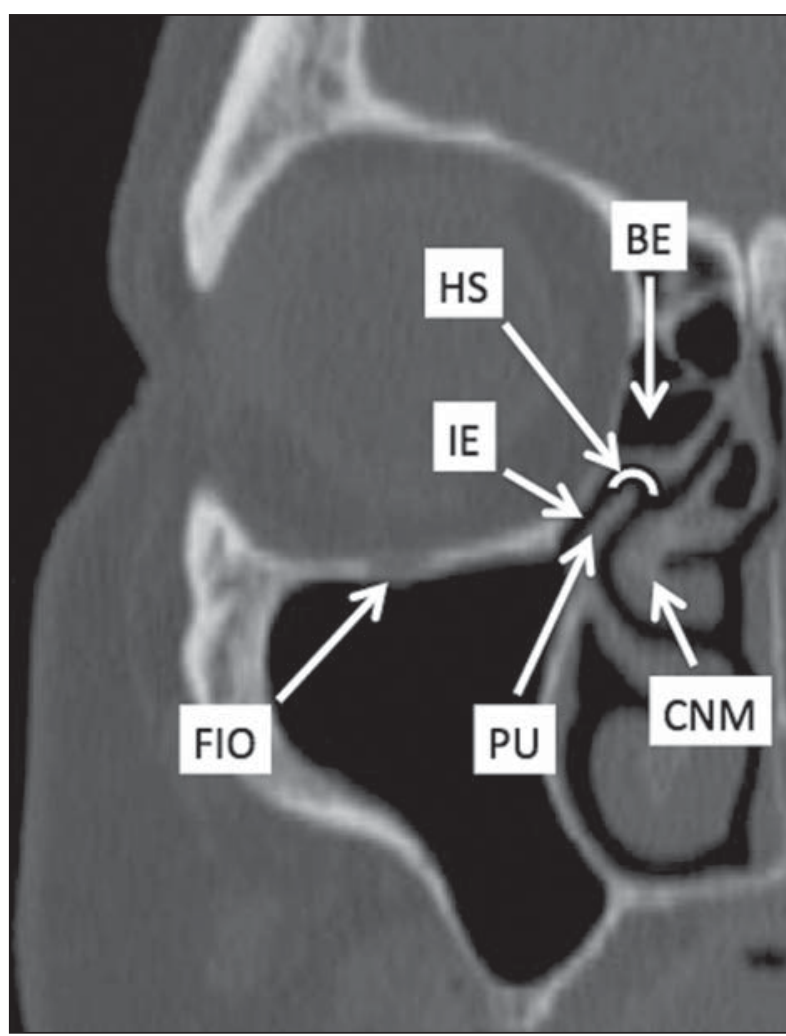

Figura 1. Imagem no plano coronal demonstrando os componentes e relações anatômicas da unidade ostiomeatal. Em destaque: bulla etmoidal (BE), concha nasal média (CNM), hiato semilunar (HS), infundíbulo etmoidal (IE), processo uncinado $(\mathrm{PU})$, forame orbitário inferior (FIO), parte não integrante da unidade ostiomeatal.

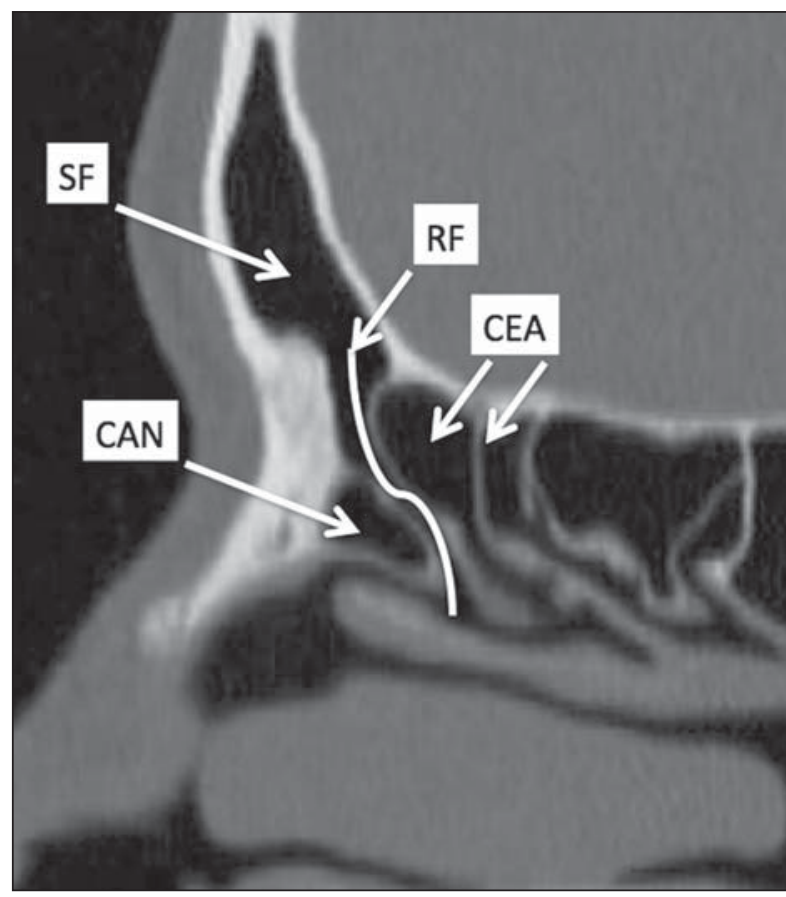

Figura 2. Anatomia do recesso frontal (RF) no plano sagital e sua relação com as células etmoidais anteriores (CEA). Em destaque: a célula do agger nasi (CAN) e o seio frontal (SF). 0 recesso frontal é a via de drenagem do seio frontal e de algumas células do agger nasi, que geralmente tem forma de funil.

uma estrutura bem pequena próxima à linha média, posteriormente ao corneto superior, entre a parede anterior do seio esfenoidal e a parede posterior das células etmoidais $^{(\mathbf{1 3})}$ (Figura 3).

\section{Célula do agger nasi}

Células do agger nasi, descritas inicialmente por H. Meyer ${ }^{(\mathbf{1 5})}$, são as células etmoidais mais anteriores, presentes em até $98 \%$ dos casos. Suas paredes anterior e 
posterior formam parte das paredes do recesso frontal e correspondem endoscopicamente a um abaulamento na parede nasal anteriormente à inserção do corneto médio ${ }^{(\mathbf{1 6})}$. As células do agger nasi são mais bem vistas nas imagens sagitais e coronais (Figura 4). Anormalidades relacionadas às células do agger nasi são causas frequentes de revisão nas cirurgias endoscópicas endonasais $^{(17)}$.

\section{Células frontais}

Células frontais, ou células de Kuhn ${ }^{(\mathbf{1 2})}$, são células etmoidais intimamente relacionadas às células do agger nasi. De acordo com o seu padrão de pneumatização, as células frontais podem ser divididas em quatro diferentes tipos (tipos I a IV). De longe as mais comuns, as células frontais tipo I são células únicas, localizadas acima da célula do agger nasi e inferiormente ao assoalho do seio frontal (Figura 5). As células frontais tipo II são duas ou mais células etmoidais anteriores que se pneumatizam acima da célula do agger nasi, podendo ter extensão até o interior do seio frontal (Figura 6). As células frontais tipo III são células etmoidais anteriores únicas, que devido ao seu grande volume se pneumatizam acima da célula do agger nasi,

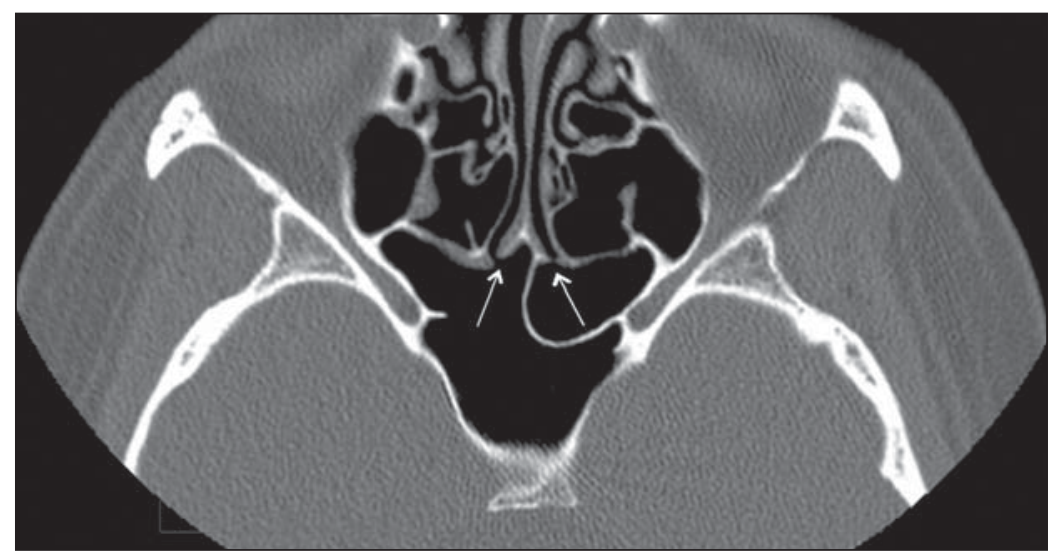

Figura 3. Imagem no plano axial ao nível dos recessos esfenoetmoidais (setas). 0 recesso esfenoetmoidal é mais bem visto nas imagens no plano axial e drena os seios esfenoidais e algumas células etmoidais posteriores.

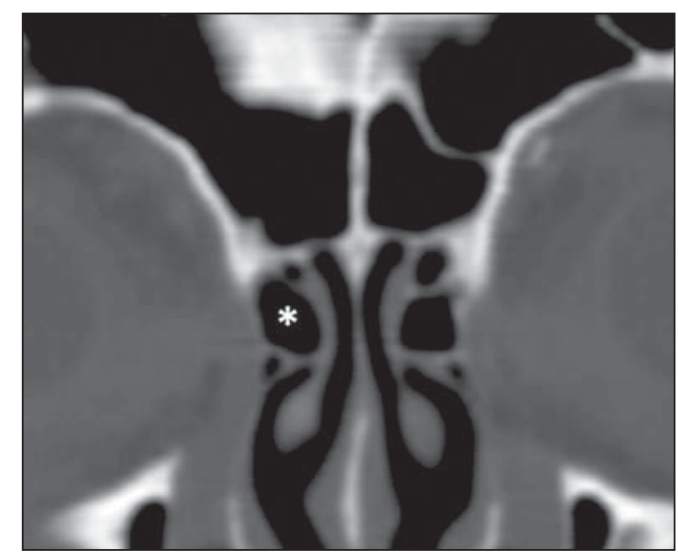

Figura 4. Imagem no plano coronal ao nível das células do agger nasi em destaque (asterisco). Células do agger nasi são consideradas as células etmoidais mais anteriores.
Figura 5. Imagens nos planos coronal (A) e sagital (B) evidenciando as células frontais do tipo I (setas) e sua íntima relação com as células do agger nasi (asteriscos). Células frontais do tipo I são únicas e não se estendem para o interior do seio frontal.

Figura 6. Imagens nos planos sagital (A) e coronal (B) evidenciando células frontais do tipo II (setas). Células frontais do tipo II têm o aspecto de "escada" de duas ou mais células e localizam-se acima das células do agger nasi (CAN).
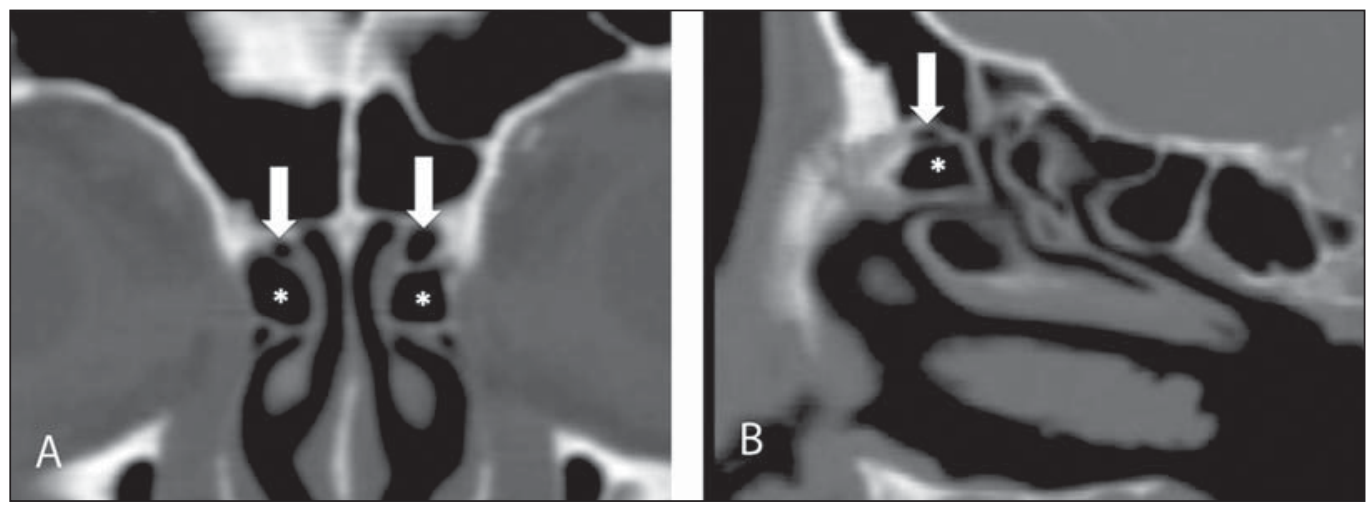

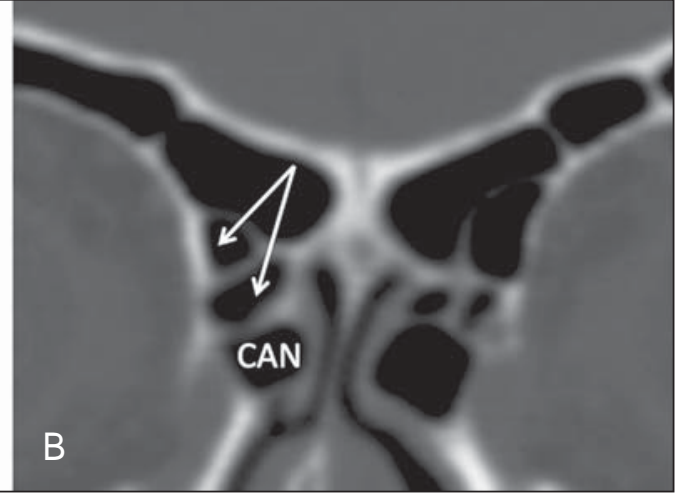


estendendo-se cefalicamente para o interior do seio frontal (Figura 7). Menos frequentes, as células frontais tipo IV são células isoladas localizadas no interior do seio frontal, acima da célula do agger nasi (Figura 8) ${ }^{\mathbf{( 1 3 )}}$. Park et al. encontraram uma célula frontal em $32 \%$ dos 105 pacientes estudados e prevalência de células frontais tipos I a IV de, respectivamente, 24,2\%, $4,2 \%, 3,1 \%$ e $0 \%{ }^{(\mathbf{1 8})}$.

\section{Célula etmoidal supraorbital}

Célula etmoidal supraorbital é a célula etmoidal que se estende na direção supe- rolateral entre a parede medial da órbita e o teto do etmoide (Figura 9) ${ }^{(\mathbf{1 3})}$. Células etmoidais supraorbitais podem simular múltiplos seios frontais, célula frontal tipo III, células suprabullares, células frontais bullares ou células do septo interfrontal nas imagens coronais de TC. De acordo com Zhang et al., sua incidência pode chegar a $5,4 \%^{(19)}$.

\section{Células de Haller}

As células de Haller, também conhecidas como células orbitomaxilares, foram descritas inicialmente por Albert von Hal- ler em $1743^{(\mathbf{2 0})}$. Trata-se de células etmoidais extramurais que se pneumatizam inferiormente ao assoalho orbitário, estendendo-se desde o labirinto etmoidal, abaixo da bulla etmoidal, em direção ao interior do seio maxilar (Figura 10). Devido à sua localização, próximo à unidade ostiomeatal, e dependendo do seu número e tamanho, podem causar obstrução da drenagem mucociliar e estarem relacionadas a sinusopatia $^{(\mathbf{1 3})}$. De acordo com Stackpole e Edelstein, células de Haller estão presentes em $34 \%$ dos pacientes com sinusopatia. Além disso, esses autores demonstraram que
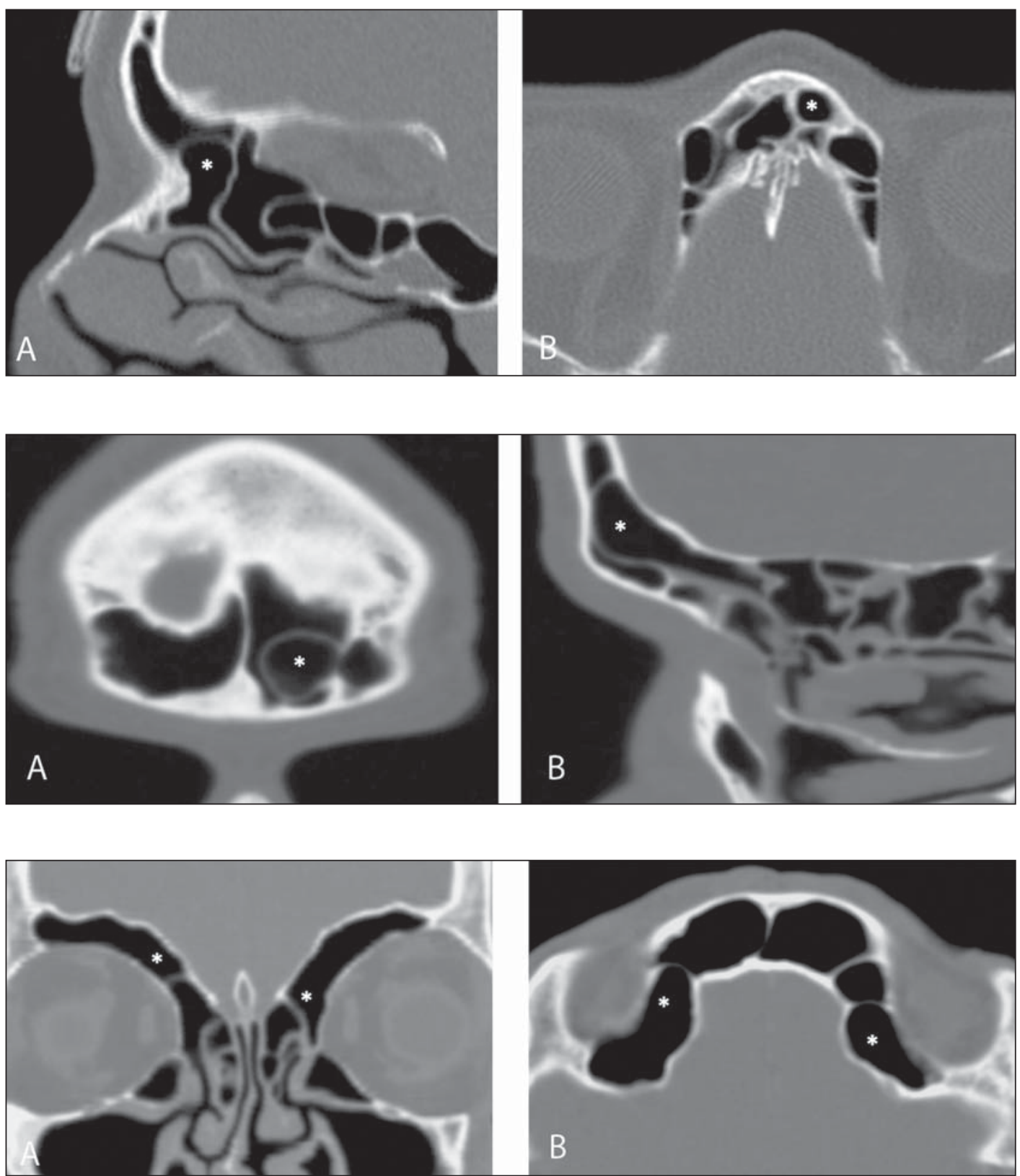

Figura 7. Imagens nos planos sagital oblíquo $(\mathbf{A})$ e axial (B) evidenciando uma célula frontal do tipo III (asterisco), que se estende para o interior do seio frontal. Células frontais do tipo III também localizam-se acima das células do agger nasi, não incluídas nessas imagens.

Figura 8. Imagens nos planos coronal (A) e sagital oblíquo (B) demonstrando uma célula frontal do tipo IV (asterisco). Células frontais do tipo IV são geralmente únicas e localizam-se isoladamente no interior dos seios frontais.

Figura 9. Imagens nos planos coronal (A) e axial (B) demonstrando as células etmoidais supraorbitais (asteriscos). Tais células pneumatizam-se acima do assoalho das órbitas, podendo causar a impressão de seios frontais septados. Células etmoidais supraorbitais são mais bem identificadas nos cortes coronais e axiais. 
quanto maior a célula de Haller, maiores as chances de inflamação dos seios maxila$\operatorname{res}^{(21)}$.

\section{Células de Onodi}

Também conhecidas como células esfenoetmoidais, as células de Onodi foram inicialmente descritas pelo laringologista húngaro Adolf Onodi, em 1904 ${ }^{(22)}$. Células de Onodi são consideradas as células etmoidais mais posteriores. Dados recentes so- bre a prevalência de células de Onodi em estudos de TC, principalmente usando técnicas mais modernas, são raros. De acordo com estudos anatômicos em cadáveres, as células de Onodi são bastante comuns, com prevalência variando de $39 \%$ a $60 \%{ }^{(\mathbf{2 3 , 2 4})}$. A existência de um septo horizontal dividindo os seios esfenoidais em "dois andares" sugere a presença de uma célula de Onodi (Figura 11). Células de Onodi estão intimamente relacionadas com os nervos
Figura 10. Céulas de Haller (asteriscos). Células etmoidais que se pneumatizam inferiormente às órbitas para o interior dos seios maxilares. Em situações especiais podem reduzir a unidade ostiomeatal e predispor à obstrução do infundíbulo maxilar.

Figura 11. Imagem no plano coronal demonstrando uma célula de Onodi (asterisco) imediatamente abaixo do canal do nervo óptico. 0 aspecto de seio esfenoidal de "dois andares" no plano coronal ajuda na identificação deste tipo de célula.
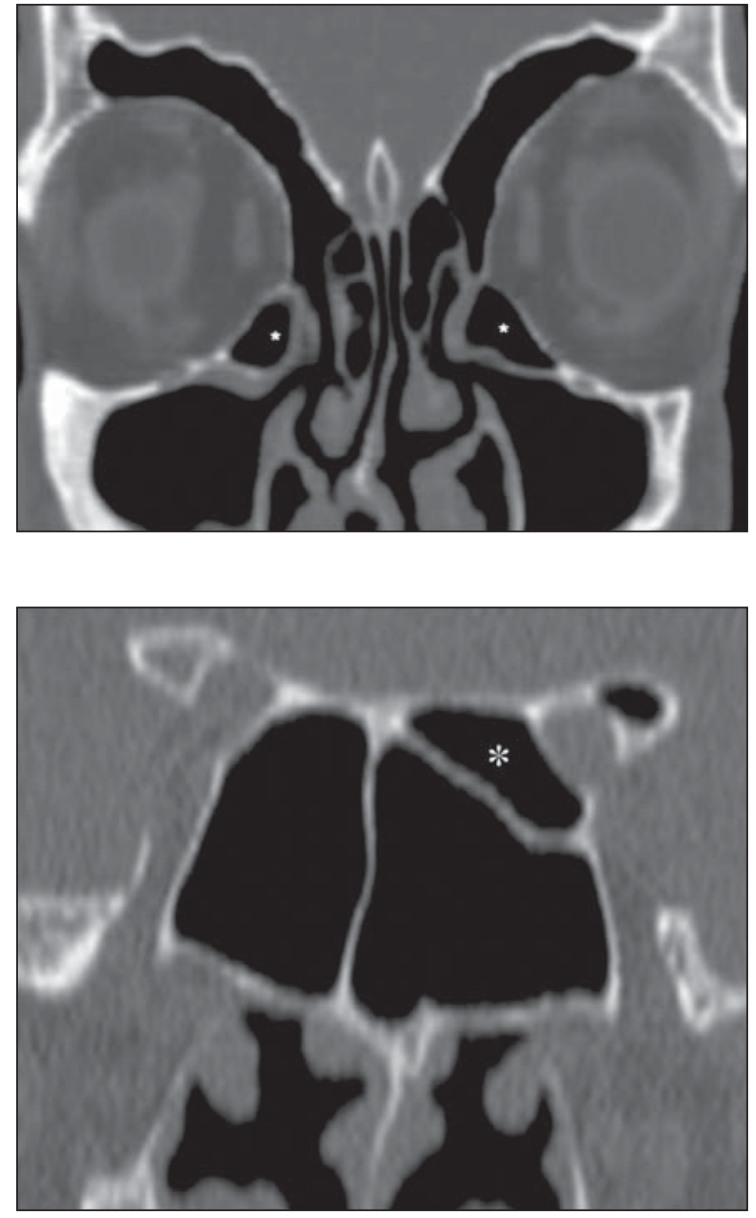

ópticos e artérias carótidas internas, daí a sua importância clínica no caso de sinusopatia dos seios esfenoidais ${ }^{(\mathbf{1 3})}$.

\section{Célula frontal bullar}

Célula frontal bullar é uma célula etmoidal localizada acima da bulla etmoidal que se pneumatiza ao longo da base do crânio em direção ao seio frontal, podendo causar convexidade no seu assoalho (Figura $12)^{(7,23)}$. De acordo com Park et al., sua prevalência pode chegar a $10 \%{ }^{(\mathbf{1 8})}$.

\section{Célula suprabullar}

Células suprabullares são células etmoidais também localizadas acima da bulla etmoidal, que como as células frontais bullares são mais bem visualizadas nas reformatações sagitais. A célula suprabullar se diferencia da célula frontal bullar porque sua borda anterior não se estende até o seio frontal (Figura 13) $)^{(7,25)}$. De acordo com Park et al., sua prevalência é em torno de $8 \%{ }^{(\mathbf{1 8})}$.

\section{Bulla etmoidal}

Classicamente, bulla etmoidal é descrita como a maior e mais constante das células etmoidais anteriores. Bulla etmoidal é tida como uma célula etmoidal intramural em íntima relação com a unidade ostiomeatal, acolada à lâmina papirácea e que drena para o meato médio através de um trato pneumatizado retrobullar $^{(26)}$ (Figura 1). Em razão da sua consistência, a bulla etmoidal é um reparo importante para o rinologista. Além disso, juntamente com o processo uncinado, define o hiato semilunar, a via de saída para o infundíbulo etmoidal, localizado na parede lateral da fossa nasal ${ }^{(\mathbf{1 3 - 1 5})}$. Wright e Bolger ${ }^{(26)}$, após análise macroscópica minuciosa de 14 fossas nasais de 8 espécimens, verificaram que todas as bullas

Figura 12. Imagens nos planos sagital oblíquo (A) e axial (B) demonstrando uma célula frontal bullar (asterisco) e sua relação com a base do crânio e o seio frontal. A borda anterior de uma célula frontal bullar não se estende para o interior dos seios frontais.

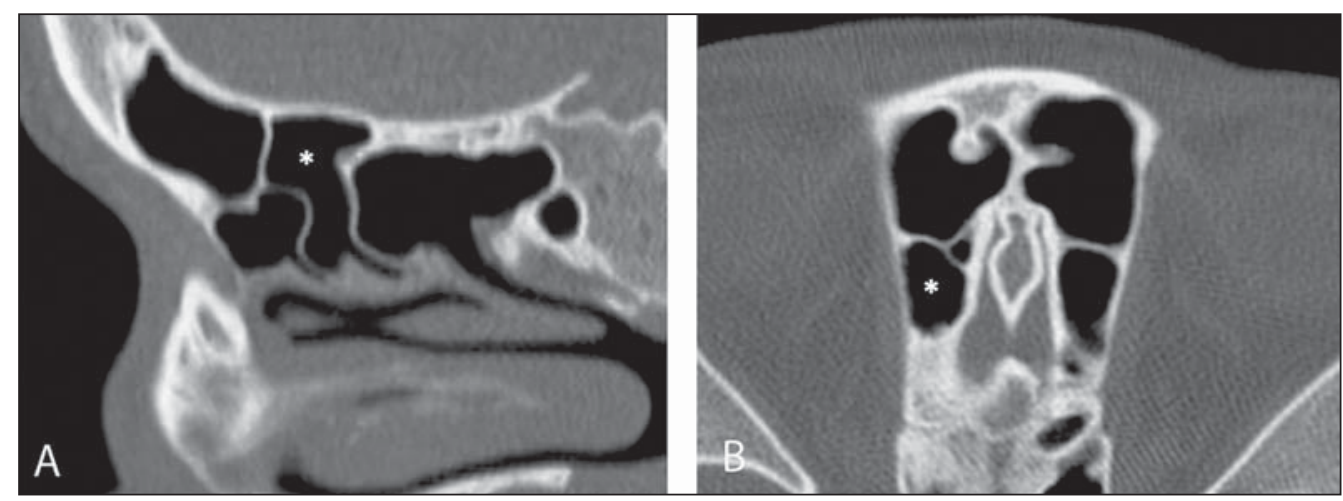



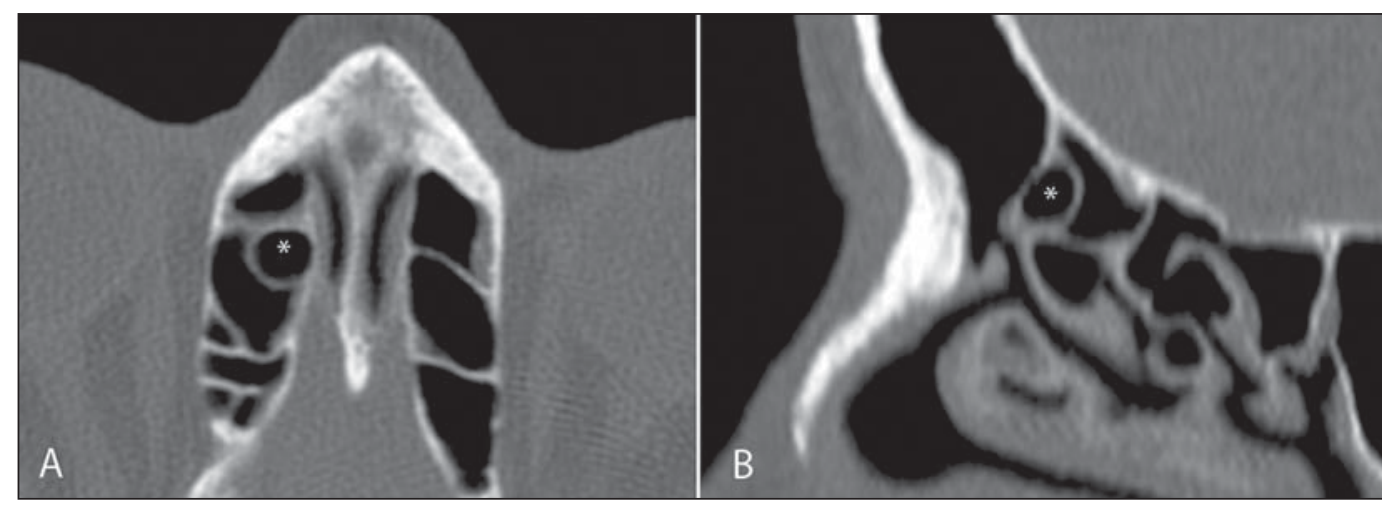

Figura 13. Imagens nos planos axial (A) e sagital (B) demonstrando uma célula frontal bullar à direita (asterisco). A célula frontal bullar se diferencia da célula suprabullar, pois sua borda anterior se estende até o seio frontal.

etmoidais possuíam parede posterior incompleta independentemente de seu grau de pneumatização e da presença de septações internas. De acordo com esses autores, é discutível se as bullas etmoidais realmente representam uma célula verdadeira ou se devem ser tratadas como uma lamela. Apesar de conhecida como bulla etmoidal desde 1893 (Zuckerkandl ${ }^{(27)}$ ), segundo os autores, "de uma perspectiva anatômica, bulla não é, todavia, a melhor descrição para tal estrutura",(26).

\section{CONCLUSÃO}

O desenvolvimento do labirinto etmoidal é um processo heterogêneo e variável. Deste intricado processo originam-se dois grupos específicos de células: as células etmoidais extramurais e intramurais. Imagens de TC com reformatação em múltiplos planos fornecem maiores detalhes anatômicos e resolução espacial para o estudo da anatomia dos seios paranasais. O reconhecimento das variantes anatômicas nos estudos dos seios paranasais pode ser útil ao médico assistente no manejo do paciente com sinusopatia. $\mathrm{O}$ aprimoramento das cirurgias endoscópicas minimamente invasivas dos seios paranasais provavelmente aumentará a demanda por relatórios com detalhes anatômicos mais minuciosos dos seios paranasais e suas variantes.

\section{REFERÊNCIAS}

1. Kountakis SE, Senior BA, Draf W. The frontal sinus. Berlin: Springer-Verlag; 2005.
2. Aygun N, Zinreich SJ. Imaging for functional endoscopic sinus surgery. Otolaryngol Clin North Am. 2006;39:403-16, vii.

3. Batra PS. Radiologic imaging in rhinosinusitis. Cleve Clin J Med. 2004;71:886-8.

4. Beale TJ, Madani G, Morley SJ. Imaging of the paranasal sinuses and nasal cavity: normal anatomy and clinically relevant anatomical variants. Semin Ultrasound CT MR. 2009;30:2-16.

5. Isaacs SJ, Goyal P. Comparison between threedimensional and triplanar computed tomography imaging of the frontal recess. Am J Rhinol Allergy. 2009;23:502-5.

6. Kew J, Rees GL, Close D, et al. Multiplanar reconstructed computed tomography images improves depiction and understanding of the anatomy of the frontal sinus and recess. Am J Rhinol. 2002;16:119-23.

7. Bradley DT, Kountakis SE. The role of agger nasi air cells in patients requiring revision endoscopic frontal sinus surgery. Otolaryngol Head Neck Surg. 2004;131:525-7.

8. Ramadan HH. Revision endoscopic sinus surgery in children: surgical causes of failure. Laryngoscope. 2009;119:1214-7.

9. Osguthorpe JD. Surgical causes of failure in endoscopic sinus surgery. Laryngoscope. 2000;110: 177.

10. Ramadan HH. Surgical causes of failure in endoscopic sinus surgery. Laryngoscope. 1999;109: 27-9.

11. Scuderi AJ, Harnsberger HR, Boyer RS. Pneumatization of the paranasal sinuses: normal features of importance to the accurate interpretation of CT scans and MR images. AJR Am J Roentgenol. 1993;160:1101-4.

12. Bent JP, Cuilty-Siller C, Kuhn FA. The frontal cell as a cause of frontal sinus obstruction. Am J Rhinol. 1994;8:185-91.

13. Coates MH, Whyte AM, Earwaker JW. Frontal recess air cells: spectrum of CT appearances. Australas Radiol. 2003;47:4-10.

14. Laine FJ, Smoker WR. The ostiomeatal unit and endoscopic surgery: anatomy, variations, and imaging findings in inflammatory diseases. AJR Am J Roentgenol. 1992;159:849-57.
15. Meyer H. Lehrbuch der Anatomie. Leipzig; 1861.

16. Earwaker J. Anatomic variants in sinonasal CT. Radiographics. 1993;13:381-415.

17. Eskiizmir GA. The role of agger nasi air cells in revision endoscopic sinus surgery. Otolaryngol Head Neck Surg. 2005;133:464; author reply 465.

18. Park SS, Yoon BN, Cho KS, et al. Pneumatization pattern of the frontal recess: relationship of the anterior-to-posterior length of frontal isthmus and/or frontal recess with the volume of agger nasi cell. Clin Exp Otorhinolaryngol. 2010;3:7683.

19. Zhang L, Han D, Ge W, et al. Computed tomographic and endoscopic analysis of supraorbital ethmoid cells. Otolaryngol Head Neck Surg. 2007;137:562-8.

20. Haller A. Praelectiones academicae in proprias institutiones rei medicae/Hermanni Boerhaave. Vol. IV. Vandenhoeck, Gottingae; 1743. p. 43.

21. Stackpole AS, Edelstein DR. The anatomic relevance of the Haller cell in sinusitis. Am J Rhinol. 1997;11:219-23.

22. Onodi A. Die Sehstoerungen und Erblidung nasalen Ursprunges, bedingt durch Erkrankungen der hinteren Nebenhoehlen. Z Augenheilkd. 1904;12:23-46.

23. Driben JS, Bolger WE, Robles HA, et al. The reliability of computerized tomographic detection of the Onodi (sphenoethmoid) cell. Am J Rhinol. 1998;12:105-11.

24. Thanaviratananich S, Chaisiwamongkol K, Kraitkrakul S, et al. The prevalence of an Onodi cell in adult Thai cadavers. Ear Nose Throat J. 2003;82:200-4.

25. Landsberg R, Friedman, M. A computer-assisted anatomical study of the nasofrontal region. Laryngoscope. 2001;111:2125-30.

26. Wright ED, Bolger WE. The bulla ethmoidalis: lamella or a true cell? J Otolaryngol. 2001;30: 162-6.

27. Zuckerkandl E. Normale und pathologische Anatomie der Nasenhöhle und ihrer pneumatischen Anhänge. Vol 1. Wien: Wilhelm Braumüller; 1893. 